\title{
Determination of mass balances and ionic balances in animal manure
}

\author{
J. JAPENGA \& K. HARMSEN \\ Institute for Soil Fertility Research, P.O. Box 30003, NL 9750 RA Haren, Netherlands \\ Received 18 January 1990; accepted 14 March 1990
}

\begin{abstract}
Liquid and solid fractions of three different pig slurry samples and a poultry manure sample were isolated through high speed centrifugation followed by ultrafiltration. The gross ionic composition of the liquid manure fractions could be described by: $\mathrm{K}+, \mathrm{Na}^{+}, \mathrm{Ca}^{2+}, \mathrm{Mg}^{2+}$, $\mathrm{Cl}^{-}$, bicarbonate, weakly acidic cations (ammonium) and weakly alkaline anions (acetate). Ionic balances showed an agreement of more than $98 \%$ between anionic and cationic species. The elemental composition of a pig slurry solid fraction was determined. Mass calculations based on this analysis accounted for $98 \%$ of the total weight.
\end{abstract}

Keywords: alkalinity, analysis, animal manure, cations, liquid fraction, nutrients, volatile fatty acids

\section{Introduction}

In recent years the application of large quantities of animal manures ${ }^{1}$ to agricultural soils has created environmental problems in the Netherlands. The adverse environmental effects associated with the application of manure include the following: 1. Part of the acidification of forest soils in the Netherlands is considered to be due to atmospheric deposition of ammonia, followed by nitrification. Most of the ammonia stems from manure applied to arable land and grassland (van Breemen et al., 1982).

2. Mobile components such as nitrate and other anions as well as potassium and other univalent cations may leach out to the groundwater. This affects the quality of drinking water sources (Cooper et al., 1984).

3. Phosphate contents in soils, due to the application of large quantities of animal manure, may reach levels of saturation or near-saturation of the phosphate-binding capacity (Gerritse et al., 1982). Surface runoff of phosphate and organic compounds may cause eutrophication of surface water.

1 In the following paragraphs the term 'manure' will be used for animal manures as well as for animal slurries. 
4. The mobility of metal ions and phosphate in the soil system may be affected by the introduction of organic matter and as a result of changes in the $\mathrm{pH}$ and redox potential after manure application (Shaviv \& Jury, 1986; Prasad et al., 1984; Field et al., 1985; Amoozegar-Fard et al., 1980).

The long-term purpose of the present study was to quantify the effect of animal manure on the solubility of metal species and phosphate in the soil aqueous phase. Solubility in combination with soil physical conditions determines metal and phosphate mobility and consequently the environmental impact of animal manure application.

An accurate description of the chemical composition of animal manure is a necessary prerequisite for this study. This paper presents the results of chemical analysis of liquid and solid fractions of animal manure.

The liquid fraction of manure is particularly important as it represents the main mobile phase during the initial period of manure/soil interaction, when microbial degradation has not yet started:

- Up to $50 \%$ of manure organic matter is present in the liquid fraction. After application of manure to agricultural soil, this dissolved organic matter (including carboxylic acid anions and phenolic compounds) is responsible for the solubilization of certain metals through complexation; these metals may originate from the manure (e.g. copper) or from the soil (e.g. aluminum, iron). A relation exists between the degree of solubilization of metals and dissolved organic matter content.

- More than $90 \%$ of the ammonium in manure occurs in the liquid fraction. After nitrification the nitrate formed is an important nutrient and potential pollutant. Potassium, sodium and chloride are also predominantly present in the liquid fraction and may cause local salinity problems in the soil.

- Acid/base buffering ions as bicarbonate, ammonium and volatile fatty acid anions constitute up to $75 \%$ of the ionic species found in the manure liquid fraction. Especially when the manure is applied to soils with a limited buffer capacity, the buffering substances from the manure liquid fraction are contributing factors that induce changes in the soil solution $\mathrm{pH}$. Acidifying effects occur upon the loss of gaseous ammonia or upon nitrification. Loss of carbon dioxide to the gaseous phase results in an increasing $\mathrm{pH}$. Rapid aerobic degradation of volatile fatty acids and other organic compounds raises the $\mathrm{pH}$ and reduces the buffer capacity of the liquid phase in the soil/manure system. The $\mathrm{pH}$ is a crucial factor, which regulates precipitation/solubilization and sorption processes in the soil/manure system. It has a direct effect on acidity-controlled precipitation/dissolution processes (e.g. calcium, magnesium, manganese salts). Indirectly the $\mathrm{pH}$ influences the concentration of organic acid anions with complexing properties (e.g. for iron, copper, aluminum) in the soil solution.

Therefore, an accurate description of the chemical composition of manure is a necessary prerequisite for the investigation of manure/soil interactions. The objectives of the present paper are:

- to describe suitable analytical methods for the determination of the chemical composition of manure,

- to develop methods to determine mass balances for manure and ionic balances 
for manure liquid fractions,

- to report results of chemical analysis of a number of animal manure samples.

\section{Materials and methods}

\section{Materials}

Two pig slurry samples (PS-1 and PS-2) and one poultry manure sample (PM) were obtained from Dutch farmers. The manures had been stored in storage tanks for several months. After sampling, the manures were analysed within a few weeks. A part of sample PS-1 was stored at $4{ }^{\circ} \mathrm{C}$ for 18 months and then analysed. As the composition had changed during storage, this sample was designated as PS- $1 / 18$ to distinguish it from the original sample PS-1.

\section{Sample pretreatment}

Samples were passed through 4-mm sieves and homogenized. After high-speed centrifugation $\left(2000 \mathrm{~g}\right.$ at $20^{\circ} \mathrm{C}$ ) the supernatant was filtered through $0.45 \mu \mathrm{m}$ filters under pressure (manual or mechanical). The centrifugation residue of sample PS$1 / 18$ was recovered from the centrifugation tube and was used for solid fraction analysis.

\section{Analytical procedures}

Most methods used are standard methods and are only briefly described. The titration procedure for acid/base buffering ionic species in manure filtrates is described in more detail. In the following outline of the analytical methods the term 'sample' means a convenient aliquot of the manure, the manure filtrate or the (wet) manure centrifugation residue, except when stated otherwise.

Total solids. Total solids content of the manures and of the solid fractions of manure were determined by overnight drying at $105^{\circ} \mathrm{C}$ and weighing.

$p H$, redox potential (Eh). $\mathrm{pH}$ and redox potential (Eh) were measured electrochemically in the freshly prepared filtrate.

Metal ions. The sample was digested by heating it to $150^{\circ} \mathrm{C}$ in a mixture of sulfuric acid and nitric acid (1:3) on a sand bath. Small amounts of nitric acid were added to replace nitric acid lost due to evaporation until the mixture became slightly yellow to colourless. After cooling, dilution and filtration, lanthanum nitrate was added to avoid phoshate interference. Metal concentrations were determined on a flameAAS or carbon furnace-AAS apparatus.

Phosphate. The sample was boiled with dilute sulfuric acid, in the presence of some potassium persulfate. After filtration the colorimetric reagent (an acid solution of 
ammonium heptamolybdate and potassium antimonyl tartrate) and ascorbic acid were added. Absorption was measured at $882 \mathrm{~nm}$. This determination gave the total phosphate concentration.

Orthophosphate was determined by the same method as that used for the total phosphate determination except that:

- the mixture was not boiled but kept at room temperature,

- no potassium persulfate was added.

Carbon dioxide. Inorganic carbon was determined as carbon dioxide by measuring the volume of gas formed after addition of a strong acid.

Chloride. The sample was ashed at $550{ }^{\circ} \mathrm{C}$ in the presence of magnesium oxide, to maintain weakly alkaline conditions. The resulting alkaline ash was dissolved in a minimum amount of concentrated nitric acid and then diluted. Chloride was titrated with a standard solution of mercuric nitrate and a diphenylcarbazide solution in ethanol as the indicator.

Total sulfur. The alkaline ash of the sample (cf. the chloride determination), was redissolved in nitric acid and the sulfate concentration was determined gravimetrically as barium sulfate.

Total nitrogen. Total nitrogen was determined by a simple Kjeldahl technique without the use of nitrate-reducing catalysts, as nitrates were considered absent at the low redox potential of the manure samples.

Chemical oxygen demand (COD value). The sample was heated with a known amount of potassium dichromate in dilute sulfuric acid. The amount of dichromate not used up in the oxidation process was determined through titration with ferrous ion.

Acid/base buffering ionic species. Manure filtrate (1-2 ml) was diluted with $\mathrm{CO}_{2}$ free distilled water to a volume of $200 \mathrm{ml}$. The solution was transferred to polythene beakers of $275 \mathrm{ml}$ capacity, sealed with parafilm sheet and stored until analysis within 2 hours. The $\mathrm{pH}$ was raised to about 9 by rapidly adding $1 \mathrm{M} \mathrm{NaOH}$ to the sample solution under limited access of air. Standard $1 \mathrm{M} \mathrm{HCl}$ solution was slowly added under moderate stirring until the first $\left(\mathrm{HCO}_{3}^{-}\right)$equivalence point was reached at $\mathrm{pH}=7.8$. This $\mathrm{pH}$ was considered the starting point of the titration. Standard $\mathrm{HC} 1$ solution was then added rapidly to $\mathrm{pH}=2.8$. The solution was transferred to a 500$\mathrm{ml}$ glass beaker and nitrogen was passed through the solution using a medium size glass frit to remove carbon dioxide ( $15 \mathrm{~min}$ at a rate of $0.21 \mathrm{~min}^{-1}$ ); the solution was then returned to the polythene vessel and titrated under moderate stirring with the standard $1 \mathrm{M} \mathrm{NaOH}$ solution, adding fixed volumes of $0.025 \mathrm{ml}$ and measuring $\mathrm{pH}$ after every addition. Neutrality at $\mathrm{pH}=7.0$ was determined exactly through slow addition of small portions of the $\mathrm{NaOH}$ solution near this equivalence point. The addition was then continued up to $\mathrm{pH}=11.2$ by introducing fixed volumes of 


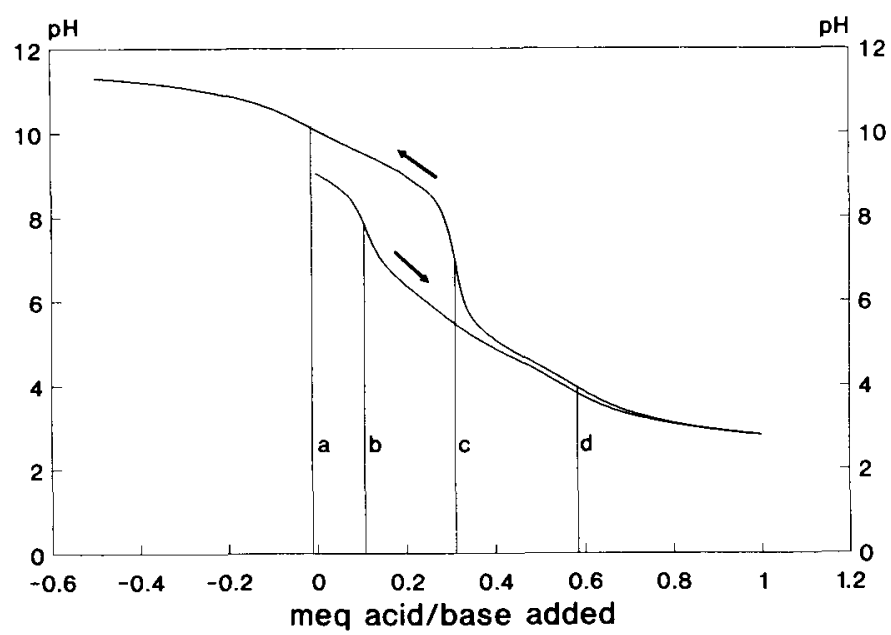

Fig. 1. Titration curve for the determination of acid/base buffering ions in manure filtrate solutions, indicating the equivalence points.

$0.025 \mathrm{ml}$ and measuring $\mathrm{pH}$ after every addition.

Concentrations were calculated from equivalence points obtained from the titration curves for the onward $(\mathrm{HCl})$ titration and for the backward $(\mathrm{NaOH})$ titration as shown in Fig. 1. The point designated $b$ is the starting point of the titration at $\mathrm{pH}=7.8$. Point $\mathrm{c}$ is the strong acid/base equivalence point at $\mathrm{pH}=7.0$ and points $\mathrm{d}$ and $\mathrm{a}$ are the equivalence points for total weak base (mainly volatile fatty acid anions) and total weak acid (mainly ammonium ion), respectively. Points $d$ and a were determined using the excess strong acid/base calculation method, introduced by Gran (1952) and adapted in our laboratory for manure filtrate samples (Japenga, unpublished; Fordham \& Schwertmann, 1977).

The concentrations can be calculated as follows:

- weak acid (ammonium ion): $(c-a) / w$ meq $\mathrm{g}^{-1}$,

- weak base (volatile fatty acid anion): $d-c) / w$ meq $\mathrm{g}^{-1}$,

- bicarbonate: $(c-b) / w$ meq $g^{-1}$,

where $w$ is the sample weight.

Organic matter. An aliquot of the centrifugation residue was mixed in a 1:10 ratio with $1 \mathrm{M} \mathrm{HC1}$ in order to remove carbonates, chloride, ammonium ion and other ionic components. This mixture was centrifuged again and the residue was washed twice with water $(1: 10)$ and centrifuged. The final centrifugation residue was dried at $105^{\circ} \mathrm{C}$ and weighed. Part of the dry acid-washed centrifugation residue was then ignited at $850^{\circ} \mathrm{C}$; the weight loss upon ignition can be attributed entirely to the oxidative decomposition of organic matter.

Silica. The ignition residue (cf. the organic matter determination) was treated several times with concentrated nitric acid and the remaining insoluble matter was weighed 


\section{J. JAPENGA AND K. HARMSEN}

and dried for 4 hours at $180^{\circ} \mathrm{C}$. The residue dissolved (slowly but completely) in hydrofluoric acid, and was thus considered to be silica.

\section{Results}

The gross chemical composition of the manure samples used in this study is summarized in Table 1. For samples PS-1, PS-2 and PM, the concentrations were determined through direct analysis; for sample PS-1/18, most concentrations were calculated from the values obtained separately for the solid and liquid fractions (Tables 2 and 3 ). The results are in good agreement with average values obtained at routine laboratories in the Netherlands and can be considered to be representative for animal manure, except for phosphorus contents, which were lower than average values.

The chemical composition of the liquid fractions of the manure samples is given in Table 2. The percentages inorganic carbon were calculated from the bicarbonate values.

Table 3 gives the chemical composition of the solid fraction of sample PS-1/18. All elements were determined in the wet centrifugation residue. Results are expressed on a dry weight basis. The wet centrifugation residue amounted to $11.8 \%$ of the original manure. Total solids content of the centrifugation residue (determined through heating overnight at $105^{\circ} \mathrm{C}$ ) was $26.4 \%$. The percentages of the different fractions were calculated as follows:

Table 1. Chemical composition of manure samples (concentrations given in $\mathrm{g} \mathrm{kg}^{-1}$ ).

\begin{tabular}{|c|c|c|c|c|}
\hline & \multicolumn{4}{|c|}{ Sample } \\
\hline & PS-1 & PS-2 & PM & PS- $1 / 18$ \\
\hline Total solids & 70 & 46 & 183 & 51.6 \\
\hline $\mathrm{COD}$ & 53 & 43 & 96 & 26.7 \\
\hline Inorganic carbon & 3.5 & - & 9.5 & $5.53(5.47 \mathrm{a})$ \\
\hline K & 6.0 & 5.3 & 6.3 & $5.85^{a}$ \\
\hline $\mathrm{Na}$ & 0.60 & 0.7 & 1.3 & $0.601^{a}$ \\
\hline $\mathrm{Ca}$ & 1.3 & 0.7 & 24.0 & $1.30^{\mathrm{a}}$ \\
\hline $\mathrm{Mg}$ & 0.51 & 0.3 & 1.8 & $0.504^{a}$ \\
\hline $\mathrm{Fe}$ & 0.14 & 0.08 & 0.33 & $0.148^{a}$ \\
\hline $\mathrm{Mn}$ & 0.018 & 0.010 & 0.061 & $0.0172^{\mathrm{a}}$ \\
\hline $\mathrm{Cu}$ & 0.032 & - & 0.025 & $0.032^{\mathrm{a}}$ \\
\hline $\mathrm{Al}$ & - & - & - & $0.157^{\mathrm{a}}$ \\
\hline $\mathrm{Cl}$ & 2.9 & - & 3.5 & $2.73^{a}$ \\
\hline$P$ & 0.5 & - & 5.2 & $0.458^{a}$ \\
\hline $\mathrm{S}$ & 1.4 & - & - & $1.19 \mathrm{a}$ \\
\hline $\mathrm{N}$-inorganic & - & - & - & $5.60 \mathrm{a}$ \\
\hline Silica & - & - & - & $1.2^{\mathrm{a}}$ \\
\hline
\end{tabular}

a Calculated from the concentrations obtained for the solid fraction and for the liquid fraction. 
- percentage manure centrifugation residue: $\mathrm{CR}=11.8 \%$

- percentage supernatant: $\mathrm{C}=100-\mathrm{CR}=88.2 \%$

- total solids in centrifugation residue: $\mathrm{SC}=26.4 \%$

- total solids in orginal manure: $\mathrm{SM}=5.16 \%$

- total solids in liquid fraction: $A=(100 \times \mathrm{SM}-\mathrm{SC} \times \mathrm{CR}) / \mathrm{C}=2.32 \%$

- percentage solid fraction: $\mathrm{S}=(\mathrm{SC}-\mathrm{A}) \times \mathrm{CR} /(100-\mathrm{A})=2.91 \%$

- percentage liquid fraction: $L=100-\mathrm{S}=97.1 \%$

Therefore the solid fraction of sample PS-1/18 was $2.91 \%$ of the manure, not taking into account volatile material in the solid fraction itself (which presumably is a very small quantity).

$11.8 \mathrm{~g}$ of the centrifugation residue contained $2.91 \mathrm{~g}$ of solid fraction corresponding to $24.7 \%$ solid fraction and $75.3 \%$ liquid fraction. The concentrations of the elements in the solid fraction were calculated from the concentrations determined in the wet centrifugation residue $\left(C_{\mathrm{wc}}\right)$ and in the filtrate $\left(C_{1}\right)$ (see Table 2):

$$
C_{\mathrm{s}}=\left(C_{\mathrm{wc}}-0.753 \times C_{1}\right) / 0.247
$$

Table 2. Chemical composition of the manure liquid fractions (filtrates) (concentrations given in $\mathrm{g} \mathrm{kg}^{-1}$ unless stated otherwise).

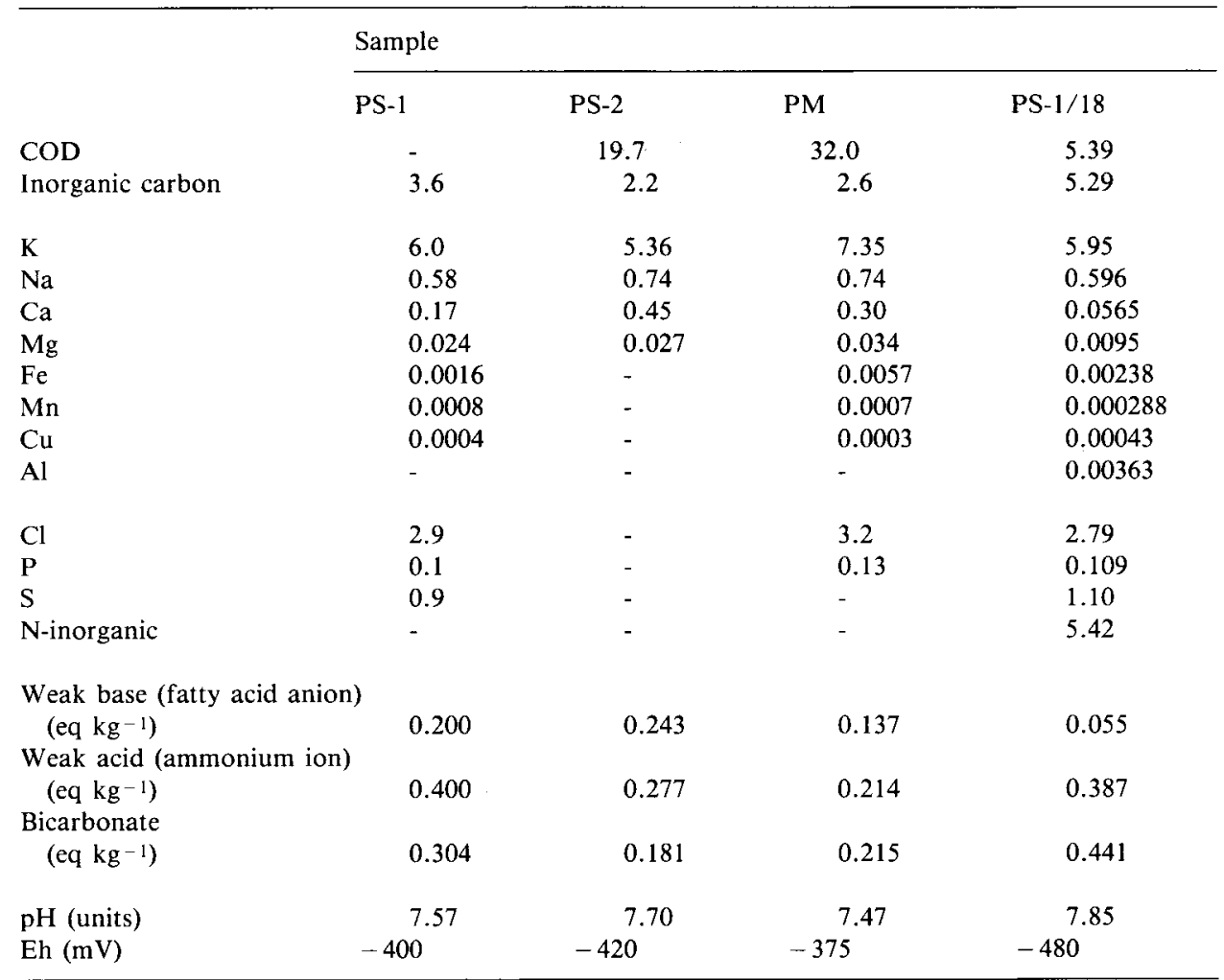


Table 3. Chemical composition of the solid fraction of sample PS-1/18 (concentrations given in $\mathrm{g} \mathrm{kg}^{-1}$ ).

\begin{tabular}{lc}
\hline & Sample PS-1/18 \\
COD & 736.0 \\
Organic matter & 736.0 \\
Inorganic carbon & 11.36 \\
$\mathrm{~K}$ & \\
$\mathrm{Na}$ & 2.68 \\
$\mathrm{Ca}$ & 0.75 \\
$\mathrm{Mg}$ & 42.8 \\
$\mathrm{Fe}$ & 17.0 \\
$\mathrm{Mn}$ & 4.99 \\
$\mathrm{Cu}$ & 0.58 \\
$\mathrm{Al}$ & 1.09 \\
& 5.26 \\
$\mathrm{Cl}$ & 0.7 \\
$\mathrm{P}$ & 12.09 \\
$\mathrm{~S}$ & 4.06 \\
$\mathrm{~N}$-inorganic & 11.7 \\
$\mathrm{~N}$-organic & 28 \\
Silica & 41 \\
\hline
\end{tabular}

\section{Discussion}

\section{Ionic balance of manure liquid fractions}

The analytical results summarized in Table 2 show that eight different ionic species determine the gross ionic composition of the manure liquid fraction. Major species include $\mathrm{Na}^{+}, \mathrm{K}^{+}, \mathrm{Cl}^{-}$, weakly alkaline anions (volatile fatty acid anions), weakly acidic cations (ammonium ion) and bicarbonate; $\mathrm{Ca}^{2}+$ and $\mathrm{Mg}^{2}+$ occur in smaller amounts. Substantial amounts of phosphorus are present also. About $50 \%$ of total phosphorus in manure filtrates is organically bound. Concentrations of inorganic phosphates (mainly orthophosphate) were estimated to be about $0.005 \mathrm{eq} \mathrm{kg}^{-1} \mathrm{ma}-$ nure liquid fraction as calculated from Table 2 . It is not necessary to include phosphates in the ionic balance because they are included in the titrimetrically determined weakly alkaline anions concentration. Sulfur is present in manure filtrates as organic sulfur compounds and as inorganic sulfides, as a consequence of the very low Eh values $(<-300 \mathrm{mV})$. Due to the presence of cations which effectively precipitate inorganic sulfide at the ambient $\mathrm{pH}$, sulphur will be present in the liquid fraction almost exclusively as organic sulfur compounds. This leads to the conclusion that sulfur compounds do not contribute significantly to the ionic balance.

The ionic balance for the liquid fractions of manure samples PS-1, PS-2, PM and PS- $1 / 18$ can be calculated as follows.

The equivalent concentrations of the metal ions of interest $(\mathrm{Na}, \mathrm{K}, \mathrm{Ca}, \mathrm{Mg}, \mathrm{Al})$ and chloride were calculated from Table 2. 
In Table 2 the concentrations of weak base (volatile fatty acid anion), weak acid (ammonium ion) and bicarbonate are expressed as eq $\mathrm{kg}^{-1}$. The relative concentration of the different ionic and nonionic species can be computed from their dissociation constants. Results are given for filtrates with $\mathrm{pH}$ values ranging between $\mathrm{pH}$ $=7.5$ and $\mathrm{pH}=7.85$, taking into account an estimated ionic strength $(I=0.55)$ for the sample; the fatty acid present is considered to be acetic acid:

\begin{tabular}{llrrr}
\hline & & $\mathrm{pH}=7.5$ & $\mathrm{pH}=7.7$ & $\mathrm{pH}=7.85$ \\
'weak base' & free acetic acid & $0.06 \%$ & $0.05 \%$ & $0.03 \%$ \\
& acetate ion & $99.94 \%$ & $99.95 \%$ & $99.97 \%$ \\
'weak acid' & ammonia & $0.99 \%$ & $1.56 \%$ & $2.18 \%$ \\
& ammonium ion & $99.01 \%$ & $98.44 \%$ & $97.82 \%$ \\
'bicarbonate' & carbonic acid & $4.31 \%$ & $2.72 \%$ & $1.96 \%$ \\
& bicarbonate & $95.24 \%$ & $96.56 \%$ & $97.02 \%$ \\
& carbonate & $0.45 \%$ & $0.72 \%$ & $1.2 \%$ \\
\hline
\end{tabular}

giving the following electrical charges:

\begin{tabular}{llll}
\hline & $\mathrm{pH}=7.5$ & $\mathrm{pH}=7.7$ & $\mathrm{pH}=7.85$ \\
'weak base' & 1.000 & 1.000 & 1.000 \\
'weak acid' & 0.990 & 0.984 & 0.978 \\
'bicarbonate' & 0.961 & 0.980 & 0.991 \\
\hline
\end{tabular}

This means that all electrical charges are close to unity; in reality the electrical charges will be even closer to unity, because of ion pair formation in the manure filtrate at its high ionic strength: especially potassium bicarbonate and ammonium bicarbonate ion pairs increase the bicarbonate and ammonium concentration at the expense of non-charged carbonic acid and ammonia.

For typical manure filtrates estimated net charges, corrected for ion pair formation, are:

\begin{tabular}{llll}
\hline & $\mathrm{pH}=7.5$ & $\mathrm{pH}=7.7$ & $\mathrm{pH}=7.85$ \\
'weak base' & 1.00 & 1.00 & 1.00 \\
'weak acid' & 0.99 & 0.99 & 0.98 \\
'bicarbonate' & 0.97 & 0.98 & 0.99 \\
\hline
\end{tabular}

Corrections for the deviation from unity do not seem necessary for $\mathrm{pH}$ values between 7.5 and 7.9 (normal manure values); even if those corrections are carried out, the correction for 'weak acid' (cations) and 'bicarbonate' (anions) are about the same and do not change the ionic balance substantially.

Concentrations in eq kg-1 for all ionic species with concentrations $>0.001 \mathrm{eq} \mathrm{kg-1}$ are summarized in Table 4 . No correction is considered necessary for the deviation from unit electrical charge in the case of the acid/base buffering substances for rea- 
Table 4. Equivalent concentrations of ionic species in manure liquid fractions (concentrations in eq $\mathrm{kg}^{-1}$ liquid fraction).

\begin{tabular}{lllll}
\hline & \multicolumn{2}{l}{ Sample } & & \\
\cline { 2 - 5 } & PS-1 & PS-2 & PM & PS-1/18 \\
& & & & 0.152 \\
$\mathrm{~K}$ & 0.153 & 0.137 & 0.188 & 0.026 \\
$\mathrm{Na}$ & 0.025 & 0.032 & 0.032 & 0.002 \\
$\mathrm{Ca}$ & 0.009 & 0.023 & 0.015 & 0.001 \\
$\mathrm{Mg}$ & 0.002 & 0.003 & 0.003 & 0.387 \\
Weak acid (ammonium ion) & 0.400 & 0.277 & 0.214 & 0.568 \\
Total (cationic species) & 0.589 & 0.472 & 0.452 & 0.078 \\
$\mathrm{Cl}$ & 0.082 & 0.051 & 0.092 & 0.055 \\
Weak base (fatty acid anion) & 0.200 & 0.243 & 0.137 & 0.441 \\
Bicarbonate & 0.304 & 0.181 & 0.215 & 0.574 \\
Total (anionic species) & 0.586 & 0.475 & 0.444 & \\
\hline
\end{tabular}

sons given before.

Differences between the total amount of cations and the total amount of anions do not exceed $2 \%$ in any of the samples.

The results are represented graphically in Fig. 2. Fig. 2a shows the ionic balances for the samples PS-1, PS-2 and PM. Fig. 2b demonstrates the effect of ageing on the ionic balances: sample PS-1 is compared with sample PS-1/18.

From Fig. $2 \mathrm{~b}$ and from Tables 2 and 4 the following effects of ageing can be observed:

- A decrease in volatile fatty acid anion ('weak base') content accompanied by an equivalent increase in bicarbonate concentration, caused by biological degradation processes.

- Calcium and magnesium levels decreased (as well as manganese levels). This can be attributed to the precipitation of acid-soluble salts such as carbonates and fits with the increase in $\mathrm{pH}$ from 7.57 to 7.85 . The increase in carbonate-species concentrations (bicarbonate) in the solutions also enhances precipitation. Furthermore, sample PS-1 may have been supersaturated so that slow precipitation occurred during storage.

- Iron and copper concentrations increased slightly. This can be explained by the increase in high molecular dissolved organic matter concentration, associated with the increase of $\mathrm{pH}$. The dependency of metal solubilities on $\mathrm{pH}$ and dissolved organic matter content was confirmed by other experiments.

The ionic balance of the sample PS-2 liquid fraction was checked by comparing it with an artificial manure liquid fraction, prepared from the following chemical substances:

- $14.31 \mathrm{~g}$ ammonium bicarbonate,

- $1.98 \mathrm{~g}$ calcium chloride bihydrate, 


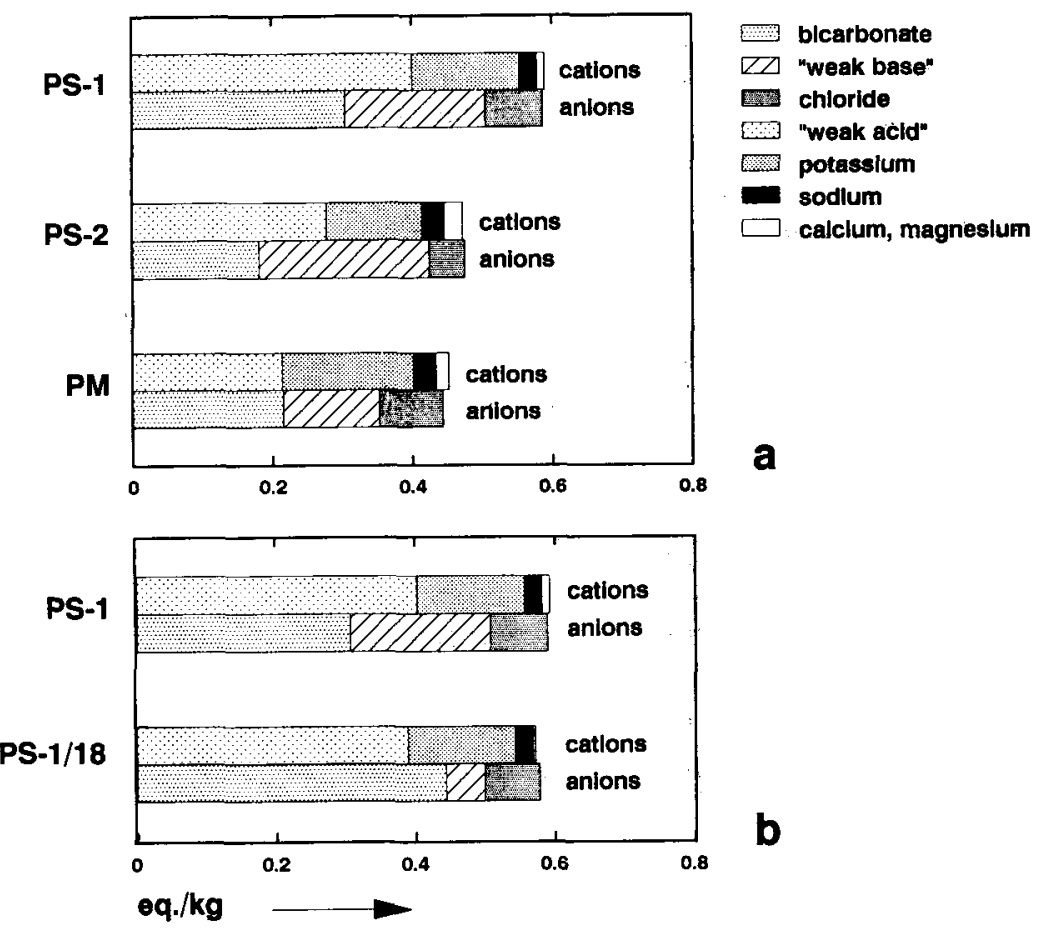

Fig. 2. (a) Ionic balances for manure liquid fractions of PS-1, PS-2 and Pm. (b) Effect of ageing on the ionic balances of pig slurry liquid fraction PS-1.

$-8.82 \mathrm{~g}$ acetic acid,

- $1.79 \mathrm{~g}$ potassium chloride,

- $7.40 \mathrm{~g}$ ammonium acetate,

- $114 \mathrm{ml} 1 \mathrm{M}$ potassium hydroxide,

- $33 \mathrm{ml} 1 \mathrm{M}$ sodium hydroxide.

These salts were dissolved in minimal amounts of water, mixed and diluted to 1 litre. This solution approached the chemical composition of the manure liquid fraction from sample PS-2. A small quantity of precipitate was formed (calcium carbonate). Aliquots of this stock solution and of fresh manure filtrate from sample PS-2 were diluted tenfold. The electrical conductivities were compared, showing a value only $0.3 \%$ lower in the case of the prepared solution. This further supports the reliability of the ionic balances determined.

Mass balances of sample PS-1/18

From the chemical composition of sample PS-1/18 (Table 1) and of its solid fraction (Table 3), the mass balance could be estimated for the total manure and for the solid fraction. 
Table 5. Estimation of the chemical composition of sample PS-1/18 and of the solid fraction of manure sample PS-1/18 (concentrations in $\mathrm{g} \mathrm{kg}^{-1}$ ).

\begin{tabular}{|c|c|c|}
\hline & \multicolumn{2}{|l|}{ Sample } \\
\hline & PS- $1 / 18$ & $\begin{array}{l}\text { PS-1/18 } \\
\text { (solid fraction) }\end{array}$ \\
\hline Organic matter & 26.7 & 736 \\
\hline Carbon dioxide & 20.1 & 41.7 \\
\hline $\mathrm{K}_{2} \mathrm{O}$ & 7.0 & 3.2 \\
\hline $\mathrm{Na}_{2} \mathrm{O}$ & 0.8 & 1.0 \\
\hline $\mathrm{CaO}$ & 1.8 & 59.9 \\
\hline $\mathrm{MgO}$ & 0.8 & 28.3 \\
\hline $\mathrm{FeO}$ & 0.2 & 6.4 \\
\hline $\mathrm{MnO}$ & 0.0 & 0.7 \\
\hline $\mathrm{CuO}$ & 0.0 & 1.4 \\
\hline $\mathrm{Al}_{2} \mathrm{O}_{3}$ & 0.3 & 9.9 \\
\hline $\mathrm{Cl}$ & 2.7 & 0.7 \\
\hline $\mathrm{P}_{2} \mathrm{O}_{5}$ & 1.0 & 27.7 \\
\hline $\mathrm{s}$ & 1.2 & 4.1 \\
\hline $\mathrm{NH}_{3}$ & 6.8 & 14.2 \\
\hline Silica & 1.2 & 41 \\
\hline Total calculated & 70.6 & 976 \\
\hline Total determined & 74.5 & 1000 \\
\hline Mass acounted for & $95 \%$ & $98 \%$ \\
\hline
\end{tabular}

Table 5 represents the composition of sample PS-1/18 and of the sample PS-1/18 solid fraction. Values from Table 1 and 3 were used with the following modifications:

- metal species are represented as oxides,

- inorganic nitrogen is represented as ammonia,

- sulfur is represented as sulfide,

- phosphorus is represented as phosphorus pentoxide,

- inorganic carbon is represented as carbon dioxide.

These species will be the approximate 'building stones' of the compounds present in sample PS- $1 / 18$ and in the sample PS-1/18 solid fraction; only an additional unknown amount of hydrogen is present in the components. The total solids content of sample PS-1/18 was computed from data in Table 5 (first column) and equals $70.6 \mathrm{~g} \mathrm{~kg}^{-1}$. The experimentally determined total solids content is $51.6 \mathrm{~g} \mathrm{~kg}^{-1}$. Considering, however, that ammonium ion is predominantly present in the liquid phase and that at $\mathrm{pH}$ values of 7-8 inorganic carbon in the liquid phase is present as bicarbonate, it may be expected that during drying at $105^{\circ} \mathrm{C}$ a major part of the ammonium bicarbonate decomposed and evaporated as ammonia and carbon dioxide; together with $6.4 \mathrm{~g} \mathrm{~kg}^{-1}$ ammonia from the liquid fraction, $16.5 \mathrm{~g} \mathrm{~kg}^{-1}$ of car- 
bon dioxide can evaporate. This gives a corrected experimental total solids content of $51.6+6.4+16.5=74.5 \mathrm{~g} \mathrm{~kg}^{-1}$ in the case of total evaporation of ammonium bicarbonate from the liquid fraction; this agrees reasonably well with the calculated value $\left(70.6 \mathrm{~g} \mathrm{~kg}^{-1}\right)$.

From the calculated and corrected experimentally determined values a mass balance coefficient can be calculated:

(1) MB (sample PS-1/18) $=70.6 / 74.5=0.95$

The missing $5 \%$ can be ascribed, at least partially, to hydrogen in the dry matter present in salts as hydrogenophosphates, as crystal water or as strongly adsorbed water.

For the solid fraction of manure sample PS- $1 / 18$, Table 5 shows a calculated total solids content of $976 \mathrm{~g} \mathrm{~kg}^{-1}$. The mass balance coefficient can be calculated now:

(2) $\mathrm{MB}$ (sample PS-1/18 solid fraction) $=976 / 1000=0.98$

The missing $2 \%$ can be accounted for by the presence of hydrogen in the dry material. Analytical inaccuracies (especially in the relationship between organic carbon and organic matter content and in the DOC measurement itself) may be of some importance too.

In Fig. 3 the mass balances are presented; the sum of the experimentally determined total solids content and the amount of ammonium bicarbonate considered to be evaporated during drying is taken as $100 \%$ in the case of sample PS- $1 / 18$.

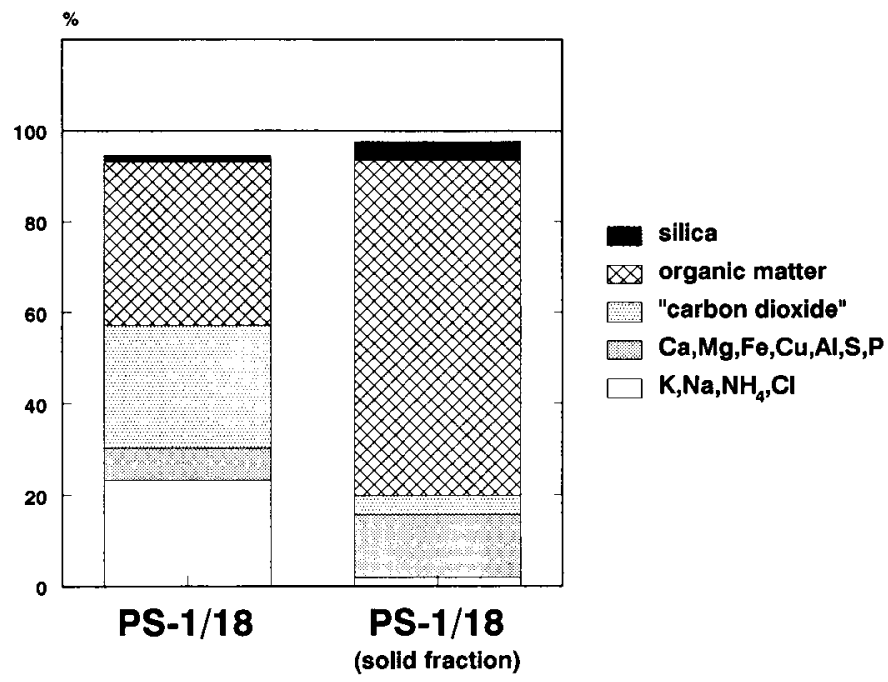

Fig. 3. Calculated mass for sample PS-1/18 and for the solid fraction of sample PS-1/18. 


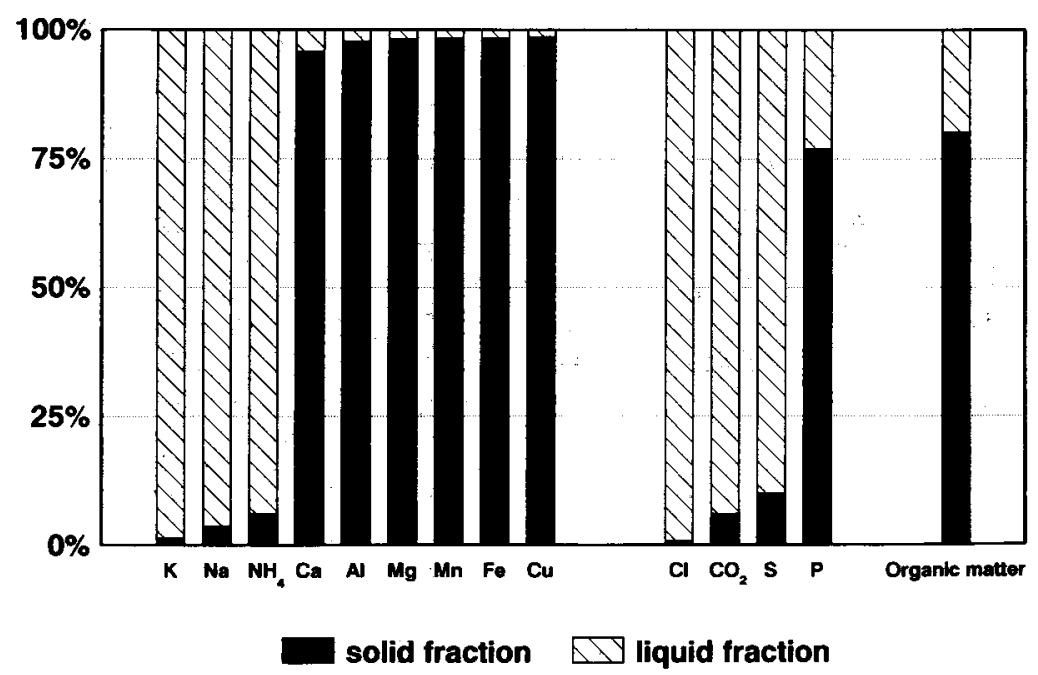

Fig. 4. Distribution of components over the solid and liquid fractions of sample PS-1/18.

\section{Distribution ratios}

The distribution of main manure components between the two fractions was calculated based on concentrations in the two fractions and the relative amounts of the fractions (liquid fraction $97.1 \%$; solid fraction $2.91 \%$ ). The results are given in Fig. 4.

Distribution ratios can be calculated too:

$$
k=C_{\mathrm{s}} / C_{I}
$$

in which:

$C_{\mathrm{s}}=$ concentration in the solid fraction,

$C_{1}=$ concentration in the liquid fraction.

Values for $C_{\mathrm{s}}$ and $C_{1}$ are obtained from Tables 3 and 2, respectively, and the resulting values for the distribution ratio $k$ are summarized in Table 6 .

\section{Conclusion}

The results given for the mass balances and ionic balances in the manure chemical system show that with a limited number of chemical analyses (using standard procedures) a good description of the manure chemical system can be given. Reliable data sets obtained in this way can be used for the development and subsequent testing of a chemodynamical model of the soil/manure system.

Ionic balances for manure solid fractions can be determined as soon as reliable analytical methods will be available for distinguishing between inorganically and organically bound sulfur and phosphorus. 
Table 6. Distribution ratios between the solid and liquid fractions of sample PS-1/18 $\left(k=C_{\mathrm{s}} / C_{1}\right)$.

\begin{tabular}{lc}
\hline & Sample PS-1/18 \\
Organic carbon & 135 \\
Inorganic carbon & 2.1 \\
$\mathrm{~K}$ & 0.5 \\
$\mathrm{Na}$ & 1.3 \\
$\mathrm{Ca}$ & 750 \\
$\mathrm{Mg}$ & 1800 \\
$\mathrm{Fe}$ & 2100 \\
$\mathrm{Mn}$ & 2000 \\
$\mathrm{Cu}$ & 2550 \\
$\mathrm{AI}$ & 1450 \\
$\mathrm{Cl}$ & \\
$\mathrm{P}$ & 0.3 \\
$\mathrm{~S}$ & 110 \\
$\mathrm{~N}$-inorganic & 3.7 \\
\hline
\end{tabular}

\section{References}

Amoozegar-Fard, A., W. H. Fuller \& A. W. Warrick, 1980. The movement of salts from soils following heavy application of feedlot wastes. Journal of Environmental Quality 9: 269-273.

Breemen, N. van, P. A. Burrough, E. J. Velthorst, H. F. van Dobben, T. de Wit, T. B. Ridder \&

H. F. R. Reijnders, 1982. Soil acidification from atmospheric ammonium sulphate in forest canopy throughfall. Nature 299: 548-550.

Cooper, J. R., R. B. Reneau, W. Kroontje \& G. D. Jones, 1984. Distribution of nitrogenous compounds in a Rhodic Paleudult following heavy manure application. Journal of Environmental Quality 13: 189-193.

Field, J. A., R. B. Reneau \& W. Kroontje, 1985. Effects of anaerobically digested poultry manure on soil phosphorus adsorption and extractability. Journal of Environmental Quality 14: 105-107.

Fordham, A. W. \& U. Schwertmann, 1977. Composition and reactions of liquid manure (Gülle), with particular reference to phosphate: III. pH-buffering capacity and organic components. Journal of Environmental Quality 6: 140-144.

Gerritse, R. G., P. de Willigen \& P. A. C. Raats, 1982. Transport and fixation of phosphate in acid, homogeneous soils. III. Experimental case study of acid, sandy soil columns heavily treated with pig slurry. Agriculture and Environment 7: 175-185.

Gran, G, 1952. Determination of the equivalence point in potentiometric titrations. Analyst 77: 661-671.

Prasad, B., A. P. Singh \& M. K. Sinha, 1984. Effect of poultry manure as a source of zinc, iron and as complexing agent on zinc and iron availability and crop yield in calcareous soil. Journal of the Indian Society of Soil Science 32: 519-521.

Shaviv, A. \& W. A. Jury, 1986. Exchange, fixation, and precipitation of cations during leaching of soils amended with manure. I. Column experiments. Soil Science 141: 237-241. 